\title{
2 A realidade da fantasia e a fantasia da realidade: Borges e a fenda foucaultiana ${ }^{1}$
}

\section{Lucas Marques ${ }^{2}$}

1 Texto inicialmente apresentado no XIV Seminário Interno de Pesquisa do Grupo Cultura, Memória e Desenvolvimento, ocorrido entre os dias 20 e 22 de julho de 2011. Gostaria de agradecer a leitura atenta e comentários realizados pelo professor Edson Farias, bem como pelos demais colegas do Programa de Educação Tutorial (PET) em Sociologia da Universidade de Brasília.

2 Aluno de Graduação em Antropologia
RESUMO Quais conexões possíveis poderíamos traçar entre a obra literária de Jorge Luis Borges e a filosofia de Foucault? No prefácio de As Palavras e as Coisas, Foucault nos traça algumas sugestões. Neste artigo intento, a partir desta obra de Foucault, explorar algumas destas sugestões, relacionando-as com suas influências literárias e o modo como essa literatura - focando aqui a de Borges - possibilitou o espaço mesmo onde seu pensamento pôde ser construído. Por fim, a partir do conceito foucaultiano de heterotopia, busco de que modo essas fendas nos fazem questionar nossas próprias realidades, possibilitando-nos pensar o impensável.

PALAVRAS-CHAVE Jorge Luis Borges, Michel Foucault, Heterotopia.
ABSTRACT Which possible connections could we trace between Jorge Luis Borges' work and Foucault's philosophy? Foucault makes some suggestions in the preface of The order of things. In this article, I tried to explore some of these suggestions, relating them with his literary influences and the way in which this literature - focusing in Borges' work - allowed the possibilities where your thought takes place. Finally, based on Foucault's concept of heterotopia, I search for the way in which those slits make us question our own realities, allowing us to think about the unthinkable.

KEYWORDS Jorge Luis Borges, Michel Foucault, Heterotopia 
na Universidade de Brasília. À época, encontrava-se em seu $3^{\circ}$ semestre de graduação. Atualmente trabalha com religiões afro-brasileiras, sob uma perspectiva da antropologia das técnicas e dos objetos.

http://buscatextual. cnpq.br/buscatex tual/visualizacv. do?id=K4471129J5
Este artigo nasceu de um texto de Foucault. Do mesmo riso inquietante que, décadas atrás, perturbou as familiaridades do pensamento - ainda nosso - de Foucault, ao ler um texto de Borges. No prefácio de As Palavras e as Coisas, Foucault nos remete ao conto "O idioma analítico de John Wilkins", em que Jorge Luis Borges cita "uma certa enciclopédia chinesa" onde "os animais se dividem em: a) pertencentes ao imperador, b) embalsamados, c) domesticados, d) leitões, e) sereias, f) fabulosos, g) cães em liberdade, h) incluídos na presente classificação, i) que se agitam como loucos, j) inumeráveis, k) desenhados com um pincel muito fino de pêlo de camelo, l) et cetera, m) que acabam de quebrar a bilha, n) que de longe parecem moscas." (Foucault, 1966a, IX; Borges, 1952, 124).

Essa passagem do conto de Borges - e, creio, sua obra como um todo - inspirou Foucault a elaborar sua inquietante linha de raciocínio presente no livro, que viria a abalar todo o pensamento filosófico dali em diante. A partir daí, nos surge a seguinte questão: qual a relação existente entre a obra de Foucault e os contos de Borges? No prefácio de $A s$ palavras e as Coisas, Foucault nos aponta alguns caminhos. Assim, antes de entrarmos nesse conto de Borges, interessa-nos analisar o modo como
Foucault constrói seu pensamento n'As Palavras e as Coisas (e assim abordando o que ele chama de arqueologia) para, depois, relacionarmos com suas influências literárias - que vão de Mallarmé, passam por Blanchot e chegam a Borges - e o modo como essa literatura - focando aqui a de Borges possibilita o espaço mesmo onde seu pensamento poderá ser construído. Para isso, também, teremos que nos aprofundar no conceito de heterotopia, tal qual formulado por Foucault.

\section{A fenda foucaultiana (ou a arqueologia dos espaços ordenados)}

Em As Palavras e as Coisas, Foucault preocupa-se, em suma, com a ordem. A ordem, porém, como o espaço mesmo onde os enunciados podem ser proferidos, onde os discursos tornam-se "verdade". Para Foucault - e inspirado fortemente em Nietzsche - a ordem é essa potência que se faz ato, o espaço construído que possibilita a instauração de positividades e empiricidades. Essa experiência nua da ordem instaura o solo positivo onde as coisas poderão avizinhar-se; onde poderão, enfim, serem classificadas. A essa potência de positividades Foucault vai denominar de épistèmé. A épistèmé é, portanto, o campo "onde os conhecimentos, encarados fora de 
3 É interessante notar aqui que os enunciados não dizem respeito tanto à substancialização de palavras por coisas (ou vice-e-versa), mas antes, aos processos relacionais que possibilitam a mútua constituição dos termos. Dizem respeito às materialidades elas mesmas, e seus processos constitutivos de repetição e diferença. Poder-se-ia até indagar se não se trata aqui de uma ontologia dos processos, tal qual praticada na filosofia deleuziana, ou mesmo no estruturalismo de Lévi-Strauss. qualquer critério referente a seu valor racional ou a suas formas objetivas, enraízam sua positividade e manifestam assim uma história que não é a de sua perfeição crescente, mas, antes, a de suas condições de possibilidade" (Foucault, 1966a, XIX. Itálicos meus). É o espaço onde se entrecuzam saber e poder, palavras e coisas.

A épistèmé é permeada de discursos - permitida e construída a partir deles. Esses discursos estabelecem o objeto, possibilitando o campo dos saberes e dos conhecimentos; são dotados daquilo que Foucault vai chamar mais tarde de "regime de verdade" (Foucault, 1971). Segundo Deleuze (1986, 24) "longe de serem sínteses de palavras e coisas, longe de serem composições de frases e de preposições, os enunciados, ao contrário, são anteriores às frases ou às proposições que os supõem implicitamente, são formadores de palavras e de objetos". Os enunciados, portanto, são os que formam esses regimes de verdade ${ }^{3}$.

Assim, para dar conta desse espaço onde os enunciados são proferidos, Foucault monta séries, mostra elementos e elucida ordens, através de cortes diagonais (Deleuze, 1986) que não necessariamente seguem uma história linear. Através dessa arqueologia - análise histórico-filosófica das rupturas que possibilitam espaços de saber - Foucault se esforça "por encontrar a partir de que foram possíveis conhecimentos e teorias; segundo qual espaço de ordem se constituiu o saber; na base de qual $a$ priori histórico e no elemento de qual positividade puderam aparecer idéias, constituir-se ciências, refletir-se experiências em filosofias, formar-se racionalidades, para talvez se desarticularem e logo se desvanecerem" (Foucault, 1966a, XVIII).

Deste modo, a arqueologia, através de um corte diagonal - transversal -, define o espaço onde as coisas podem avizinhar-se; para que depois, em decorrência de rupturas, o campo de possibilidades e classificações possa mudar. Ela então foca-se nesse entremeio onde as ordens se deslocam, na transição entre regimes de verdade; na fenda que possibilita um novo espaço de saber. A arqueologia que realiza Foucault, deste modo, se volta para as fendas - fissuras que abrem, irrompem e possibilitam novas ordens (e, portanto, novas possibilidades). São essas fendas, "contra-lugares" que abalam nossos regimes de verdade, que Foucault vai dar o nome de heterotopias (Foucault, 1967).

As fendas (heterotopias) se fazem presentes durante todo o argumento de As Palavras e as Coisas. Através delas, Foucault nos mostra a transição de uma épistèmé antiga para uma épistèmé clássica 
(na passagem entre o século XVI e o século XVII); e de uma épistèmé clássica para uma épistèmé moderna (entre o século XVII e o século XIX). Para isso, o autor nos remete a imagens que, de certa forma, delineiam o espaço onde essas épistèmés surgem. Essas imagens (literárias e visuais) "antecipam” a nova épistèmé, desvanecem as imagens antigas e desvelam as novas possibilidades.

A pintura "Las meninas", de Velásquez, é a primeira imagem que Foucault se utiliza para elucidar seu pensamento. Esse quadro - assim como o conto e a obra de Borges - fornece a Foucault conceituações que lhe serão caras no decorrer da obra: o duplo da representação, a autonomização e o desdobramento da linguagem e a queda do divino concomitante com o surgimento efêmero e transitório desse duplo empírico-transcedental que é a figura do homem. É importante ressaltar as semelhanças entre o que o quadro de Velásquez suscita na análise de Foucault e a obra de Borges. Ambos se utilizam de metáforas semelhantes - como o espelho, o jogo infinito de imagens e representações - e possibilitam o desdobramento da linguagem sobre si mesma. Nesse sentido, "Las meninas" pode ser considerada uma obra-conceito do pensamento que vai seguir todo o livro. Mais do que mostrar a transição entre uma épistèmé e outra, o quadro (assim como a enciclopédia chinesa) delineia o raciocínio mesmo de Foucault.

Como já foi dito, a primeira transição de épistèmé analisada por Foucault ocorre entre o século XVI e o século XVII. Enquanto na épistèmé do século XVI as palavras e as coisas eram um só corpo - sendo a linguagem vista como uma coisa em si, instauradora de objetos -, na épistèmé do século XVII a linguagem torna-se atribuição de sentido, fazendo com que a palavra deixe de ser coisa e passe a significá-la. Passa-se, assim, de uma épistèmé da similitude para uma épistèmé da representação.

Para Foucault, a obra de Cervantes, Dom Quixote, apresenta de maneira clara essa transição. Ela é, portanto, uma fenda possível desse período. Quando Dom Quixote, no segundo momento da obra de Cervantes, começa a viver a literatura, ele torna-se o herói do mesmo, passando de um mundo de similitudes para um mundo de diferenças: torna-se então narrativa e assume sua realidade enquanto tal (Foucault, 1966a, 66). Assim, o signo não é mais semelhança, mas atribuição; a linguagem então se volta à representação. As palavras, de certa maneira, separam-se das coisas, se autonomizando e rompendo com as similitudes; porém, permanecem ligadas através da representação (Foucault, 1966a, 65). 
Como nos diz Machado (2000, 86), "a episteme clássica tem como fundamento a representação".

Ela, portanto, constrói imagens do mundo, através de ordenações e medidas, taxionomias e matemáticas, estabelecendo diferenças e identidades através da descrição de estruturas visíveis, formando um quadro de identidades e diferenças. Essa construção da ordem dá-se nos mais diversos modos de saber: na gramática geral, na história natural e na análise das riquezas.

Na passagem do século XVIII para o século XIX uma nova transição de épistèmé vai surgir. Trata-se da passagem da épistèmé clássica para a épistèmé moderna. A figura que ilustra essa fenda é a obra do Marquês de Sade. Para Foucault (1966a, 290), "Justine e Juliette [obras de Sade], no nascimento da cultura moderna, estão talvez na mesma posição que Dom Quixote entre o renascimento e o classicismo”. Para ele, Sade permite que a obscura violência repetida do desejo ultrapasse os limites da representação, desenrolando o quadro das identidades e das diferenças. "Sade atinge a extremidade do discurso e do pensamento clássicos. Reina exatamente em seu limite" (Foucault, 1966a, 292). Através da violência do desejo, a representação então se desdobra sobre si mesma.
Porém, como nos lembra Motta (2009), o nascimento dessa épistèmé moderna só pôde ser possível no entrecruzamento da obra Sade com a filosofia de Kant. Ele é, assim, o limiar que marca e irrompe a modernidade. A partir de Kant, conhecer não se torna mais sinônimo de representar (Machado, 2000). As coisas escapam do espaço do quadro das representações, ganham forma autônoma. O fenômeno ao qual é possível o conhecimento surge a partir de uma intuição sensível. A própria noção do objeto empírico então aparece. A representação só é possível nessa épistèmé se residindo no exterior do objeto, numa espécie de mundo profundo. As coisas então deixam de ser analisadas somente em sua superfície e passam a ser vistas em sua profundidade. Daí a importância de conceitos como estrutura, vida, trabalho e linguagem.

A noção de análise de riquezas é deslocada, e o trabalho passa a ser a unidade de medida, surgindo assim o que hoje conhecemos como economia política. O mesmo acontece com a história natural que, deslocada a partir da importância dada à organização e às funções, dá lugar à noção - aqui primordial - de vida. Assim, surge a biologia e os estudos sobre a vida. A gramática geral também vai sofrer essa desarticulação. Através da flexão, a língua passa a 
ser vista como um sistema complexo - as palavras analisadas em sua relação. Já a linguagem, último a priori a se autonomizar, só pôde mudar quando mudou o ser mesmo das representações (Foucault, 1966a, 320).

Na épistèmé moderna, a linguagem se reduplica, volta-se a si indefinidamente. As palavras não mais se entrecruzam com as representações. Elas, assim, separam-se de vez das coisas. A partir desse movimento, a linguagem se dobra sobre si. Com essa autonomização da linguagem, surge a figura - recente - do homem. É então no entrecruzamento do nascimento da biologia (com o conceito de vida), da economia (com o de trabalho) e da filologia (através das flexões), que o homem surge como medida de todo o conhecimento - objeto e sujeito do saber (Foucault, 1966, 43o). Mais do que isso, doravante o homem se descobre como ser finito: temporal e histórico. Aliás, ele só é possível através dessa finitude mesma.

Machado $(2000,102)$ nos lembra que, com a biologia, a economia e a filologia, a finitude do homem se estabeleceu no nível empírico, sensível. Porém, foi somente através da filosofia - em especial a de Kant - que a finitude se "radicalizou", atingindo a própria consciência do homem. Portanto, "o homem, na analítica da finitude, é um estranho duplo empírico-transcedental, porquanto é um ser tal que nele se tomará conhecimento do que torna possível todo o conhecimento" (Foucault, 1966a, 439).

Essa idéia de que o homem é uma figura finita uma invenção recente que logo se desvaneceria - é, segundo Machado (2000), uma clara influência da filosofia de Nietzsche. Para o autor, a idéia nietzschiana da "morte de Deus" e do surgimento do super-homem - acompanhado pelo desaparecimento do próprio homem - é o que inspira Foucault a realizar sua arqueologia das ciências do homem. Mas, lembra-nos Machado (2000, 10) "essa referência a Nietzsche se deve principalmente aos literatos franceses que introduziram na França não propriamente o comentário de Nietzsche, mas, o que é muito mais importante, um estilo nietzschiano, não-dialético e não-fenomenológico, de pensamento: Bataille, Klossowski, Blanchot”. Mais adiante, ele nos diz que "em entrevistas dos anos 80, Foucault reconhecerá não só que Nietzsche, Blanchot e Bataille permitiram que ele se libertasse de Hegel e da fenomenologia, como também que leu Nietzsche 
por causa de Bataille e Bataille por causa de Blanchot" (Machado, 2000, 107). Desse modo, fica clara a influência que a literatura exerceu sobre todo o pensamento de Foucault.

Antes de adentrarmos nesse assunto, nos preocuparemos com o modo como se deu o nascimento da literatura para Foucault para, aí sim, analisarmos como essa literatura foi o espaço mesmo que permitiu que Foucault construísse seu pensamento.

Segundo Foucault (1966a, 417), o surgimento da literatura - tal qual a conhecemos hoje - só foi possível graças à épistèmé moderna. Na autonomização da linguagem, a literatura aparece como o lugar mesmo onde as palavras se reduplicam. Lá, a linguagem é levada ao infinito. Enquanto na épistèmé clássica, com o imperativo das palavras, a linguagem era silenciada, na épistèmé moderna, com o surgimento da figura do homem, o discurso se autonomiza. Assim, na modernidade, o isolamento da linguagem sobre si mesma propicia a criação de uma literatura que, não mais voltada à representação, se reduplicasse incessantemente.

A literatura, criação da épistèmé moderna, é também a que lhe é exterior; a fenda, que abre a possibilidade para que se possa pensar em outros caminhos, outros regimes de verdade. Possibilitada pela modernidade, a literatura é também seu "contra-discurso", pois contesta o estatuto da linguagem com sua função significante (Foucault, 1966a, 119). Essa reduplicação da linguagem literária, esse desdobramento indefinido, faz com que o pensamento se mantenha no exterior de onde é possível a subjetividade. Assim, o (re)aparecimento do ser da linguagem na literatura é o desaparecimento do próprio sujeito (Machado, 2000, 114-115). Na literatura moderna, o sujeito que fala não é mais o responsável pelo discurso. Segundo Foucault (1966b, 221), "a fala da fala nos leva à literatura, mas talvez também a outros caminhos, a esse exterior onde desaparece o sujeito que fala. É sem dúvida por essa razão que a reflexão ocidental hesitou por tanto tempo em pensar o ser da linguagem: como se ela tivesse pressentido o perigo que constituiria para a evidência do 'Eu sou' a experiência nua da linguagem".

É justamente nesse espaço possível que a literatura aparece como fenda, como potência possibilitadora, como heterotopia. Levando ao limite a experiência da linguagem, da finitude, da morte, da duplicação e do pensamento impensável (Foucault, 1966a, 532), a literatura é o espaço que anuncia a fragilidade da recente invenção do homem. E é aí que, junto com os surrealistas, com Kafka, Bataille, 
Blanchot, Borges e - por que não? - Nietzsche, que Foucault vai alojar seu próprio pensamento. Não é por acaso que alguns dizem que ele é o mais literário dos filósofos e o mais filosófico dos escritores (Molina, 1999).

Com o passar do tempo, nos lembra Machado (2000), Foucault deixa de tocar nesse tema que antes lhe era tão caro. Após seus escritos da década de 60, Foucault muda sua forma de pensamento. Passando da análise dos discursos à análise do poder, a literatura passa a assumir, para Foucault, um papel extremamente diferente do anterior: não mais forma de libertação do humanismo e do estatuto do "eu privilegiado", mas parte do jogo de poder imbricado nos saberes e no sujeito. Porém, vale lembrar, seu pensamento só foi possível graças ao espaço aberto pela literatura e pela obra de Nietzsche.

\section{A realidade da fantasia e a fantasia da realidade}

Assim como Dom Quixote, de Cervantes, possibilitou a épistèmé clássica, e Justine e Juliette, de Sade, conformaram a transição da épistèmé clássica para a moderna, a obra de Borges possibilitou o pensamento de Foucault. Como ele mesmo nos diz: "Este livro nasceu de um texto de Borges. Do riso que, com sua leitura, perturba todas as familiaridades do pensamento - do nosso: daquele que tem nossa idade e geografia -, abalando todas as superfícies ordenadas e todos os planos que tornam sensata para nós a profusão dos seres, fazendo vacilar e inquietando, por muito tempo, nossa prática milenar do Mesmo e do Outro" (Foucault, 1966a, IX).

Desse modo, pretendo, nesse segundo momento do texto, discorrer sobre o modo como a obra de Borges pode ser considerada essa "fenda" entre uma épistèmé moderna e outra nova forma de pensar - que é própria da obra de Foucault. Vale lembrar que, junto com Borges, outras obras podem desempenhar esse papel. Através desse corte transversal e, poderíamos dizer, também arbitrário - pretendo buscar aproximações entre Borges e Foucault, entre a literatura moderna (espaço antes creditado por Foucault como possibilitador de novas formas de pensar) e a reflexão filosófica que o próprio autor de As palavras e as Coisas produziu.

No mesmo prefácio d'As Palavras e as Coisas, Foucault nos fornece, ainda que brevemente, um conceito que considero essencial se quisermos seguir as linhas pelas quais o autor constrói sua filosofia. Trata-se do conceito de heterotopia. Falando sobre esse conceito, ele vai nos dizer que: 
As heterotopias inquietam, sem dúvida porque solapam secretamente a linguagem, porque impedem de nomear isto e aquilo, porque fracionam os nomes comuns ou os emaranham, porque arruínam de antemão a 'sintaxe', e não somente aquela que constrói frases - aquela, menos manifesta, que autoriza 'manter juntos' as palavras e as coisas [...] as heterotopias (encontradas tão freqüentemente em Borges) dessecam o propósito, estancam as palavras nelas próprias, contestam, desde a raiz, toda a possibilidade de gramática; desfazem os mitos e imprimem esterilidade ao lirismo das frases (Foucault, 1966a, XIII).

Aqui, as heterotopias são pensadas enquanto sítios de resistência a qualquer tipo de ordem. São, sobretudo, espaços que fogem, linhas de fuga, para falarmos como Deleuze (1994), processos de desterritorialização e territorialização que não são fixos, mas que escapam; que evadem. As heterotopias inquietam.

Utilizando-se sobretudo de metáforas espaciais para constituir essa "arqueologia dos espaços ordenados", Foucault vai tratar as heterotopias enquanto "não-lugares", ou seja, espaços que, como a literatura de Borges, fazem-nos abalar nossos próprios regimes de verdade. Em um texto seu menos conhecido - escrito para uma palestra em 1967, mas só publicado (sem revisão do autor) em 1984 - chamado “Of Other Spaces”, Foucault (1967) vai desenvolver esse conceito de heterotopia, porém focando-se agora no espaço enquanto entidade física. Diferentemente das utopias, as heterotopias encontram lugar no real, ainda que este lugar esteja fora de todos os outros espaços. As heterotopias (como, veremos, o Aleph ou a Biblioteca de Borges) são lugares onde estão concentrados todos os outros lugares - um espaço-outro, onde nele se revela (e, logo, se inquieta) toda a ordem existente. Além de espaços de resistência, as heterotopias revelam a ordem, como nos diz, discutindo esse conceito na obra de Foucault e Borges, Robert Topinka (2010, 55):

Heterotopias are sites in which epistemes collide and overlap, creating an intensification of knowledge. Such intensification is certainly not at odds with the practice of resistance, but shifting our emphasis from one to the other promises new insights into the primary function of heterotopias.

Para descrever as heterotopias, Focault (1967) 
propõe até a elaboração de uma descrição sistemática (uma "quase-ciência"), que ele vai chamar de "heterotopologia”, para dar conta da análise desses espaços-outros, como uma espécie de contestação simultaneamente mítica e real do espaço em que vivemos, fazendo-nos revelar as ordens que aliam poder e saber na sociedade.

Assim, é a partir da obra de Borges, tomada aqui como um espaço heterotópico, que Foucault vai revelar e desestruturar a ordem presente, desvanecendo a figura do Homem como, na orla do mar, um rosto de areia.

Voltemos, então, a certa enciclopédia chinesa.

Para Foucault, o encantamento exótico que nos produz essa enciclopédia revela o limite de nosso próprio pensamento. Esse limite se traduz na própria impossibilidade patente de se pensar isso (Foucault, 1966a, IX). Essa impossibilidade não se encontra na vizinhança das coisas, mas no lugar mesmo onde elas poderiam avizinhar-se. Assim, “os animais ‘i) que se agitam como loucos, j) inumeráveis, k) desenhados com um pincel muito fino de camelo' - onde poderiam eles jamais se encontrar; a não ser na voz imaterial que pronuncia sua enumeração, a não ser na página que a transcreve?” (Foucault, 1966a, XI). Dito de outro modo, o que nos causa estranheza não é o caráter fantástico existente nesses animais, mas a ordem alfabética que os liga e os colocam em uma série classificatória. Ou seja, é essa série (a, b, c, d...) que transgride toda a imaginação - a nossa. É essa heterotopia que fez Foucault rir durante muito tempo; um riso inquietante, desajustado. Adentrarmos agora nas obras de Borges - relacionando-as com as de Foucault - nos ajudará a melhor compreender essa inquietude provocada em nossos pensamentos. Em "O idioma analítico de John Wilkins", Borges faz uma reflexão acerca da linguagem e de seu estatuto de ordenação (e, por que não, criação) do mundo que lhe é característico. Através de certa "obra especulativa”, Wilkins vai atrás de um idioma universal. Assim, nesse idioma, cada palavra se definiria a si mesma e nenhuma seria meramente um símbolo arbitrário. Esse idioma serviria, por conta de sua especificidade, também como enciclopédia, pois, ao tomar conhecimento da palavra, dever-se-ia tomar conhecimento de tudo que ela poderia significar. Ao dividir o universo em 40 categorias, subdivididas em diferenças que, por sua vez, se subdividiriam em espécies, Wilkins não escapa, entretanto, das ambiguidades características da classificação. E é ai que Borges aproxima o idioma criado por Wilkins da "certa enciclopédia chinesa" que Foucault 
cita em seu prefácio. Essas ambiguidades servem para mostrar, como nos diz Borges, que "não há classificação do universo que não seja arbitrária e conjectural. A razão disso é muito simples: não sabemos o que é o universo" (Borges, 1952, 124). O autor vai ainda mais longe ao questionar o estatuto orgânico e unificador que permeia esse conceito abstrato e ambicioso que é o universo (Borges, 1952, 125).

À luz do texto supracitado - e após as reflexões aqui apresentadas - podemos delinear algumas aproximações entre a obra de Borges com o pensamento foucaultiano. Ao falar sobre a arbitrariedade-conjectural que permeia a classificação do universo - portanto, das palavras e das coisas -, Borges nos diz, assim como Foucault, que há ordem; porém, essa ordem não é universal, orgânica. Como nos diz Menezes (2008, 22), “a assertiva de Borges: 'há ordem', denuncia para Foucault o a priori histórico da épistèmé na dimensão da construção da linguagem, que atravessa todo o quadro do nosso pensamento, situado em termos da sua 'idade' e 'geografia”'.

Ao falar dessa ambigüidade presente na classificação, ou seja, dessa possibilidade do "não-sentido" se ordenar em um quadro classificatório, Borges nos abre a possibilidade de pensar que essa "ordem" não é natural, tampouco universalmente legítima. A própria classificação - ou o "não-sentido" - delimita os limites do que faz sentido ou não, ou seja, do que nos é possível: em suma, de nossa épistèmé.

Esse tema se mantém em diversos outros contos de Borges. Além disso, algumas outras aproximações entre Borges e Foucault podem ser buscadas a partir da obra de Borges.

No conto "O Aleph", Borges - após a morte da personagem Beatriz Viterbo - nos leva ao encontro de Carlos Argentino Daneri, primo-irmão de Beatriz que escrevia um poema e que exercia um cargo subalterno em uma biblioteca qualquer. Após ganhar uma suposta confiança do protagonista, Daneri o apresenta ao Aleph. O Aleph "é um dos pontos do espaço que contém todos os outros pontos [...] o lugar onde estão, sem se confundirem, todos os lugares do planeta, vistos de todos os ângulos." (Borges, 1949, 145). Após uma série de requisitos necessários para visualizar o Aleph, do fundo de um porão escuro, o protagonista enfim o vê.

Nesta parte do texto, Borges interrompe a narrativa para discorrer sobre a impossibilidade do relato nessa forma linear que se dispõe a linguagem. Diante da infinitude do Aleph, sua enumeração torna-se impossível; pois não há como enumerar infinitos que se apresentam simultaneamente. O Aleph é um 
4 Cabe lembrar que os contos "O idioma Analítico de John Wilkins" e "A biblioteca de Babel" são também analisados por Menezes (2008) infinito que encerra sua infinitude na finitude que é ele próprio. Em uma esfera de aproximadamente dois ou três centímetros de diâmetro, o espaço cósmico inteiro se faz ali presente, sem diminuição de tamanho. O protagonista, então, tudo vê no Aleph, inclusive ele mesmo e o próprio Aleph - movimento que se repete infinitamente. Não fosse a inescapável ação do esquecimento, o protagonista seria capaz de reconhecer tudo o que existe ou já existiu.

O Aleph, então, é o espaço infinito, a própria heterotopia que desfigura os demais espaços. Espaço, pois delimita sua finitude em uma esfera, e infinito, pois essa finitude abarca todo o universo, toda a infinitude. É o espaço do impensável, do indizível; aquilo que está no exterior de toda a nossa épistèmé: universo que se faz universo; repetição ilimitada de todos os mundos possíveis.

O texto sobre John Wilkins não é o único de Borges que será comentado por Foucault em sua vasta obra. Outro conto nos chama a atenção, tanto por ser trabalhado por Foucault, quanto por ser possível abstrair nele parte da reflexão foucaultiana - parte que aqui nos interessa. Trata-se do conto "A biblioteca de Babel"4.

Nesse conto, "o universo (que outros chamam a

Biblioteca) constitui-se de um número indefinido, e quiçá infinito, de galerias hexagonais, com vastos poços de ventilação no centro, cercados por varandas baixíssimas" (Borges, 1941, 84). Essa biblioteca é, portanto, interminável: uma esfera cujo centro é qualquer hexágono, cuja circunferência é inacessível. Ela não tem espaço nem tempo definidos.

Dentro da Biblioteca estão todos os livros - tanto os que já existiram como os que irão existir. É possível encontrar todas as combinações possíveis dos 25 símbolos ortográficos existentes, de qualquer idioma. Qualquer série de símbolos já está lá, nalgum livro. Entretanto, não existem, em uma única prateleira sequer, dois livros idênticos. Na Biblioteca (ou no universo) tudo que é dado a expressar já está preexistente. Tudo, inclusive (acredita-se) um livro que indicaria todos os demais. Esse livro total seria o compêndio de todos os outros, o próprio sentido da existência do universo. Ademais, alerta-nos Borges, basta que um livro seja possível para que ele exista - pois na biblioteca tudo há.

Labirinto infindável e periódico de hexágonos rodeados de espelhos, a biblioteca é, pois, a multiplicação da linguagem (e do universo) ao infinito. Apesar de já ser infinita, a biblioteca ainda multiplica-se pelos espelhos e pelos livros que falam sobre ela mesma, nos revelando que "mesmo o infinito da linguagem se 
multiplica ao infinito, repetindo-se sem fim nas figuras do Mesmo" (Foucault, 1963a, 58).

Ao pensar sobre o "livro total", Foucault (1963a, 59) nos fala que ele é um "lugar sem lugar", abrigo de todos os livros possíveis, porém antes e após todos eles. Ele é, portanto, o espaço mesmo da literatura. Aqui podemos pensar que, assim como esse "livro total", o Aleph exerce o mesmo papel. Lugar sem lugar, a biblioteca e o Aleph são infinitos que se encerram em sua finitude - que se desdobram indefinidamente.

Para Motta, a "Biblioteca de Babel” é um exemplo do nascimento da literatura e, portanto, do paradoxo mesmo do ser da linguagem: essa linguagem que "retorna e consome em sua figuração outra linguagem diferente, fazendo nascer uma figura obscura mas dominadora na qual atuam a morte, o espelho e o duplo, o ondeado ao infinito das palavras" (Motta, 2009, XI). Paradoxo que, a partir de Sade, abre a possibilidade de uma épistèmé moderna, mas que, ao mesmo tempo, multiplica essa linguagem ao infinito; expurga o sujeito, se autonomiza - espaço criador para uma nova ordem em potencial. Assim, conforme Menezes (2008, 23), "a biblioteca materializa, através da linguagem, o paradoxo da noção de épistèmé na delimitação de uma ordem do espaço e das diferentes formas de organização dos saberes”.

Sustentação infinita dos fragmentos da linguagem, a Biblioteca é infinita e efêmera, real e fantástica.

Seu paradoxo é o próprio paradoxo da linguagem. A linguagem multiplicada ao infinito que, a partir daí, faz com que o próprio ser que fala desapareça. Ela aparece, portanto, nesse ponto em que se encontra o "livro total" e o Aleph: na infinitude da finitude e na finitude da infinitude; na realidade da fantasia e na fantasia da realidade. É aí que a ficção aparece como o espaço próprio da constituição desse paradoxo.

É na forma de ficção que esse saber construído sobre a realidade se desvela. Através da ficção, a linguagem se duplica e dobra-se sobre si mesma. Duplo movimento da épistèmé moderna, a ficção cria o sujeito para, logo, o desvanecer. Para Foucault, a ficção é "o que nomeia as coisas, fá-las falar e oferece na linguagem seu ser já dividido pelo soberano poder das palavras" (Foucault, 1963b, 68). Definindo o fictício, Foucault nos diz que ele é "a nervura verbal do que não existe, tal como ele é" (Foucault, 1963b, 69). Isso nos diz que é através da realidade da fantasia que a fantasia da realidade pode ser desnudada.

Daí a importância do chamado "realismo fantástico" para o pensamento do Foucault. O realismo fan- 
5 Isso se deve sobretudo ao fato de que, como nos lembra Topinka (2010), há dois conceitos distintos de heterotopia tal qual utilizado por Foucault: o primeiro é fundamentalmente textual (presente em As Palavras e as Coisas), enquanto no segundo as heterotopias são descritas como espaços físicos (aprofundado em "Of Other Spaces"). tástico desvela essa heterotopia que provocou o riso em Foucault. Mais do que a utopia, a heterotopia revela a variedade de mundos possíveis, ou mesmo impossíveis, impensáveis. Essas heterotopias estão presentes na ficção, no surrealismo, no realismo fantástico de Borges e etc. São linhas de fuga que nos inquietam, revelando-nos a ordem e fazendo-nos nos posicionar.

Espelhos, labirintos, bibliotecas, enciclopédias, deuses, universos: são essas as temáticas recorrentes de Borges (e que tanto agradaram Foucault). É interessante notar que a maioria das temáticas utilizadas por Borges, como a biblioteca, o Aleph, a Gramática e o espelho, são também temáticas semelhantes às usadas por Foucault (1966a), seja analisando o próprio Borges, seja analisando o quadro "Las Meninas", de Velásquez, seja analisando a própria linguagem. Esses espaços seriam, aqui, heterotopias par excellence. Entretanto, em "Of Other Spaces” (1967), esses espaços ocupam, quando muito, um meio caminho entre a utopia e a heterotopia, como é o caso, por exemplo, do espelho ${ }^{5}$. Em um tom de desabafo de seu próprio pensamento bem semelhante ao utilizado no prefácio d'As Palavras e as Coisas, com a leitura de Borges, Foucault diz:
From the standpoint of the mirror I discover my absence from the place where I am since I see myself over there. Starting from this gaze that is, as it were, directed toward me, from the ground of this virtual space that is on the other side of the glass, I come back toward myself; I begin again to direct my eyes toward myself and to reconstitute myself there where I am $(1967,24)$.

Todos esses elementos funcionam como fendas, heterotopias - passagem que transporta o leitor para o espaço do impensável - que o fazem questionar suas próprias realidades. Talvez por isso ele nos provoque esse riso inquietante. Textos que retornam a textos; dobras que se voltam a si. Através da ficção, Borges eleva a linguagem ao infinito que é ela mesma. Com a reduplicação da linguagem, Borges questiona nossas universalidades, arromba nossas neutralidades. E talvez aí seja onde ele mais se pareça com Foucault.

Borges, assim como Foucault, foi uma pessoa inquietante (e, mais do que isso, inquietadora). Leitor assíduo das teorias filosóficas de sua época e pensador inusitado, Borges teve grande inspiração na filosofia. Chegou a dar palestras em grandes universi- 
6 Como referência vide Borges, 1979. dades, discutindo temas aparentemente ordinários, mas através de grandes reflexões filosóficas ${ }^{6}$. Ele foi, em suma, um grande pensador, que buscou através de contos, romances e poesias mostrar que se pode pensar em outros mundos possíveis, em espaços inimagináveis, intangíveis. Borges nos revela, através da realidade da fantasia, a fantasia mesma que é a realidade - movimento que Foucault se apropria para elucidar a relação entre poder e saber, entre o que nos é possível e aquilo que nós tornamos possível. E talvez o quadro de Velásquez que Foucault evoca em seu primeiro capítulo d'As Palavras e as Coisas seja ainda o que melhor ilustre essa relação. Mesma metáfora do espelho, ali a linguagem se reduplica, fazendo com que o sujeito desapareça da cena do quadro. Assim também a biblioteca, o Aleph e a enciclopédia chinesa fazem com que, através do desdobramento sobre si próprio, o sujeito que fala desapareça, e a linguagem enfim se autonomize. Duplo-movimento (como já foi dito) que se faz possível em nossa épistèmé mas que a atravessa, irrompendo novas possibilidades.

Assim, nessa fenda possibilitadora onde se encontram Nietzsche, Blanchot, Bataille, Borges e o espaço da literatura na épistèmé moderna, podemos situar o próprio Foucault. Ele faz parte desse para- doxo que é a reduplicação indefinida da linguagem. Unir Borges e Foucault nos faz mostrar que ambos estão nessa situação de fenda. Essa possibilidade do desvanecimento do homem (como na orla do mar, um rosto de areia) se dá através de suas próprias obras. Revelar o rosto do homem significa construir essas linhas de fuga, essas heterotopias que abrem fendas. Como nos diz Agambem (1996) em um inspirador ensaio sobre O Rosto:

A revelação do rosto é a revelação da própria linguagem. Essa não tem, consequentemente, nenhum conteúdo real, não diz a verdade sobre esse ou aquele estado da alma ou de fato, sobre esse ou aquele aspecto do homem ou do mundo: é unicamente abertura, unicamente comunicabilidade. Caminhar pela luz do rosto significa ser essa abertura, padecer dela.

Ao mostrar-nos que nossos saberes são, em suma, historicizados e que mesmo o espaço do impossível pode-nos ser algum dia o espaço ordenado, Foucault e Borges arrombam nossas neutralidades, nos inquietam, pois nos posicionam.

E se, para Foucault, filosofar é pensar diferente do que se pensa, pensemos então as heterotopias. Pen- 
semos a biblioteca, o Aleph, a enciclopédia chinesa.

$\mathrm{E}$ talvez, desse riso que nos inquiete e nos cause

estranheza, possamos, ao fim e ao cabo, criar.

\section{Bibliografia}

AGAMBEM, Giorgio. 1996. "O Rosto”. Tradução de: Il volto. In: Mezzisenza fine. Note sulla politica. Bollati Boringhieri: Torino, 74-80. Retirado do blog: http://murilocorrea.blogspot.com.br/2010/o2/ traducao-o-rosto-de-giorgio-agamben.html BORGES, Jorge Luis. 1941. "A Biblioteca de Babel”. In: Ficções. Porto Alegre: Editora Globo S.A, 1972. BORGES, Jorge Luis. 1949. “O Aleph”. In.: O Aleph. São Paulo: Companhia das letras, 2008.

BORGES, Jorge Luis. 1952. "O idioma analítico de John Wilkins”. In: Outras Inquisições. São Paulo: Companhia das letras, 2007.

BORGES, Jorge Luis. 1979. Jorge Luis Borges: cinco visões pessoais. Brasília: Editora Universidade de Brasília, 1985.

DELEUZE, Gilles. 1986. Foucault. São Paulo: Brasiliense, 2005.

DELEUze, Gilles. 1994. “Desejo e Prazer”. Tradução de: Désir et Plaisir. Magazine Littéraire. Paris, n.

325 , oct, 57-65.

Foucault, Michel. 1963a. "A linguagem ao infinito". In: Ditos e Escritos III. Estética: literatura e pintura, música e cinema. Rio de Janeiro: Forense Universitária, 2009. 
FOuCAult, Michel. 1963b. "Distância, Aspecto, Origem”. In: Ditos e Escritos III. Estética: literatura e pintura, música e cinema. Rio de Janeiro: Forense Universitária, 2009.

FOUCAUlt, Michel. 1966a. As Palavras e as Coisas. São Paulo: Martins Fontes, 2007.

FoucAult, Michel. 1966b. "O Pensamento do Exterior”. In: Ditos e Escritos III. Estética: literatura e pintura, música e cinema. Rio de Janeiro: Forense Universitária, 2009.

Foucault, Michel. 1967. "Of Other Spaces”. Diacritics, Vol. 16, No. 1. (Spring, 1986), 22-27.

FOUCAULT, Michel. 1971. A ordem do discurso. São Paulo: Edições Loyola, 1996.

MACHADO, Roberto. 2000. Foucault, a filosofia e a literatura. $3^{\mathrm{a}}$ ed. Rio de Janeiro: Jorge Zahar Ed., 2005

MENEzes, Antonio Basilio Novaes Thomaz de.

[2008]. "Foucault, Borges e a experiência da linguagem”. Publicado em SABERES, Natal - RN, v. 1, n.1, dez. 2008

MOLINA, Daniel. 1999. "O filósofo que se atreveu a tudo”. Publicado em Buenos Aires: Clarín, Sección "Cultura y Nacion", 1999. Disponível em: http://vsites.unb.br/fe/tef/filoesco/foucault/bio1.pdf

MotTA, Manuel Barros da. 2009. “Apresentação”.
In.: FOUCAULT, Michel. Ditos e Escritos III. Estética: literatura e pintura, música e cinema. Rio de Janeiro: Forense Universitária, 2009. 